\title{
Low-frequency stimulation induces a pathway-specific late phase of LTP in the amygdala that is mediated by PKA and dependent on protein synthesis
}

\author{
Yan-You Huang ${ }^{1,4}$ and Eric R. Kandel ${ }^{1,2,3,4}$ \\ ${ }^{1}$ Center for Neurobiology and Behavior, College of Physicians and Surgeons of Columbia University, New York State Psychiatric \\ Institute, New York, New York 10032, USA; ${ }^{2}$ Kavli Institute for Brain Science, College of Physicians and Surgeons of Columbia \\ University, New York State Psychiatric Institute, New York, New York 10032, USA; ${ }^{3}$ Howard Hughes Medical Institute, \\ New York, New York 10032, USA
}

\begin{abstract}
Activity-dependent changes in synaptic efficacy are thought to be the key cellular mechanism for the formation and storage of both explicit and implicit memory. Different patterns of stimulation can elicit different changes in the efficiency on excitatory synaptic transmission. Here, we examined the synaptic changes in the amygdala of adult mice produced by low-frequency stimulation $(1 \mathrm{~Hz}, 15 \mathrm{~min}$, LFS). We first compared the synaptic changes induced by LFS in three different synaptic pathways of amygdala: cortical-lateral amygdala, thalamic-lateral amygdala, and lateral-basolateral amygdala pathways. We find that the plastic changes induced by LFS are different between synaptic pathways. Low-frequency stimulation selectively elicits a slow onset and protein synthesis-dependent late-phase LTP in the cortical-lateral amygdala pathway, but not in the thalamic-lateral or lateral-basolateral pathways. We next analyzed LTP induced by LFS in the cortical-lateral amygdala pathway and found that three PKA-coupling neurotransmitter receptors are involved: 5-HT4, Dopamine D1, and $\boldsymbol{\beta}$-adrenergic receptors. Antagonists of these receptors block the LFS L-LTP, but the effects of agonists of these receptors are clearly different. These results indicate that the threshold for the induction of LFS L-LTP is different among these pathways and that the maintenance of LFS L-LTP requires a cross-talk among multiple neurotransmitters.
\end{abstract}

Activity-dependent changes in synaptic efficacy have been postulated to be a key cellular model for learning and memory. Different patterns of synaptic stimulation applied to the presynaptic pathways can elicit different changes in synaptic strength, leading to either long-term synaptic potentiation (LTP) or long-term synaptic depression (LTD) (Malenka and Bear 2004). In the amygdala, high-frequency stimulation (HFS) elicits LTP and L-LTP (Huang and Kandel 1998, 2005; Huang et al. 2000; Rammes et al. $2000)$, but the effect of low-frequency $(1 \mathrm{~Hz})$ stimulation is controversial. Some reports find that $1 \mathrm{~Hz}$ (15 min) induces LTD (Wang and Gean 1999; Rammes et al. 2001; Kaschel et al. 2004; Tchekalarova and Albrecht 2007), whereas others find that the same pattern of stimulation does not induce LTD (Schroeder and Shinnick-Gallagher 2004, 2005), and may even induce LTP (Li et al. 2001; Albrecht 2007). These discrepancies could be the result of different ages of the animals, different synaptic pathways utilized, and or the different experimental conditions. Moreover, all previous studies on low-frequency stimulation (LFS) in the amygdala were focused on the synaptic changes of early phase (35-45 min after LFS). The long-term changes of synaptic plasticity induced by $1-\mathrm{Hz}$ stimulation (after $1 \mathrm{~h}$ ) are not known.

The lateral amygdala (LA) is essential for fear memory (Ledoux 2000; Blair et al. 2001). The LA receives auditory input from the thalamus directly via the thalamic-LA pathway (THLA) and receives input from the auditory cortex indirectly via the cortical-LA pathway (Ledoux 2000). One of the outputs of the LA

\footnotetext{
${ }^{4}$ Corresponding authors.
}

E-mail erk5@columbia.edu; fax (212) 543-5474.

E-mail yyh3@columbia.edu; fax (212) 543-5474.

Article is online at http://www.learnmem.org/cgi/doi/10.1101//m.593407. is the projection to the basolateral amygdala (BL) via the LA-BL pathway (Stefanacci et al. 1992). These three synaptic pathways presumably play different roles in fear memory (Amorapanth et al. 2000; Anglada-Figueroa and Quirk 2005; Corcoran and Quirk 2007). In this study, we analyzed synaptic plasticity induced by 1-Hz stimulation (15 min) in each of these three pathways (cortical-LA, TH-LA, and LA-BL) in adult animals (8-12 wk). In each case, we focused on the late phase of plastic changes $(>1 \mathrm{~h})$ induced by LFS. We specifically wanted to address the following questions: Does LFS induce LTD, or does it induce LTP in adult animals? Are there any differences in the synaptic plasticity induced by LFS in the cortical-LA, the TH-LA, and the LA-BL pathways? Are the plastic changes in any of these pathways long lasting and, if so, are they dependent on PKA and new protein synthesis, as is the case for many forms of L-LTP? Finally, we wanted to know what modulatory neurotransmitters are involved in the modulation of synaptic plasticity induced by LFS.

\section{Results}

Low-frequency stimulation at $1 \mathrm{~Hz}$ selectively induces L-LTP in the EC-LA pathway, but not in the TH-LA or LA-BL pathways

The cortical-lateral amygdala pathway (EC-LA) is a critical input to the LA, which transmits sensory information during fear conditioning (Blair et al. 2001). We first examined the synaptic changes induced by $1-\mathrm{Hz}$ stimulation (15 min, LFS) in this pathway. We found that LFS induces a slowly developed synaptic potentiation. The amplitude of field potential started to increase 20-30 min after LFS and reached a stable level $\sim 2-3 \mathrm{~h}$ after LFS 
(165 $\pm 4 \%, n=6$, measured $3.5 \mathrm{~h}$ after LFS; Fig. 1A1). The TH-LA pathway is another input conveying sensory information to the LA. Previous studies had found that L-LTP can be induced by HFS (high-frequency stimulation) in the TH-LA pathway, much as in the EC-LA pathway (Huang et al. 2000). However, for lowfrequency stimulation, we found that the synaptic changes induced in the TH-LA pathway is quite different from that induced in the EC-LA pathway. Instead of L-LTP, 1-Hz (15 min) stimulation elicited a weak synaptic depression followed by a weak synaptic potentiation in this pathway. The amplitude of field potential is $108 \pm 15 \%$ of baseline level $3.5 \mathrm{~h}$ after LFS ( $n=6$; Fig. 1B2), which is significantly different from the changes in the EC-LA pathway $(t=2.43, P<0.01)$. Finally, we examined the effect of LFS on the LA-BL synaptic pathway. This pathway is thought to be involved in the expression of fear memory (Anglada-Figueroa and Quirk 2005; Corcoran and Quirk 2007). It has been reported that in young animals LFS-induced synaptic depression in this pathway lasts $\sim 50 \mathrm{~min}$ (Wang and Gean 1999). In adult animals, however, we found that LFS first induced a transit synaptic depression lasting $\sim 30 \mathrm{~min}$, followed by a weak synaptic potentiation (115 $\pm 10 \%, n=6,3.5 \mathrm{~h}$ after LFS; Fig. 1C2). A comparison of plastic changes induced by LFS in three different pathways is shown in Figure 2B. These results indicate that the capability for the induction of LFS L-LTP is different between the pathways within the amygdala circuit $\left(F_{(2,16)}=5.5, P<0.01,3 \mathrm{~h}\right.$ after LFS). The EC-LA is the most sensitive pathway for the induction of LFS L-LTP.

LFS L-LTP in the amygdala is dependent on activation of PKA and new protein synthesis

We, therefore, focused on the modulation of LFS L-LTP in the EC-LA synaptic pathway. Previous work indicated that L-LTP in- duced by HFS in the EC-LA synaptic pathway is dependent on the activation of NMDA receptors (Huang and Kandel 1998; Blair et al. 2001). We now asked: Is L-LTP induced by LFS similarly dependent on the activation of NMDA receptors? In contrast to the L-LTP induced by HFS, we found that NMDA receptors antagonist D-APV $(50 \mu \mathrm{M})$ did not block the L-LTP induced by LFS (Control: $166 \pm 8 \%, n=5$; D-APV: $161 \pm 15 \%, n=6,3.5 \mathrm{~h}$ after LFS, $P>0.5$; Fig. 3A), indicating that LFS L-LTP is independent of NMDA receptors. Protein kinase A (PKA) cascade is an important signaling system in the maintenance of several forms of L-LTP in the hippocampus and the amygdala (Huang et al. 2000; Huang and Kandel 2005, 2007). We therefore asked: Is the L-LTP induced by LFS also mediated by PKA? As evident in Figure 3B, we found that L-LTP induced by LFS was significantly depressed in the presence of KT5720 $(1 \mu \mathrm{M})(\mathrm{KT} 5720: 111 \pm 10 \%, n=6$; Control: $166 \pm 9 \%, n=6$; measured $3.5 \mathrm{~h}$ after LFS, $t=2.57$, $P<0.01)$. Finally, previous studies in L-LTP induced by HFS and 5 -HT in the amygdala demonstrated that in each case the persistence of LTP requires new protein synthesis (Huang et al. 2000; Huang and Kandel 2007). To determine whether such a requirement also exists for the slow-onset L-LTP induced by LFS, we perfused the protein synthesis inhibitor anisomycin $(25 \mu \mathrm{M})$ into slices. We now found, surprisingly, that instead of LTP, LFS induced a synaptic depression (Control: $123 \pm 9 \%, n=6$; Anisomycin: $67 \pm 11 \%, n=6$, measured $30 \mathrm{~min}$ after LFS, $t=3.78$, $P<0.01)$. The field potential remains $88 \pm 15 \%(n=6)$ of pretetanus level $3.5 \mathrm{~h}$ after LFS, which is still significantly different from the L-LTP in control experiments $(165 \pm 10 \%, n=6$, $t=4.75, P<0.01$; Fig. 3C). These results indicate that the blockade of anisomycin on LFS L-LTP is different from the blockade on HFS L-LTP in the amygdala, in which anisomycin selectively blocks the late phase of LTP (Huang et al. 2000). It appears that
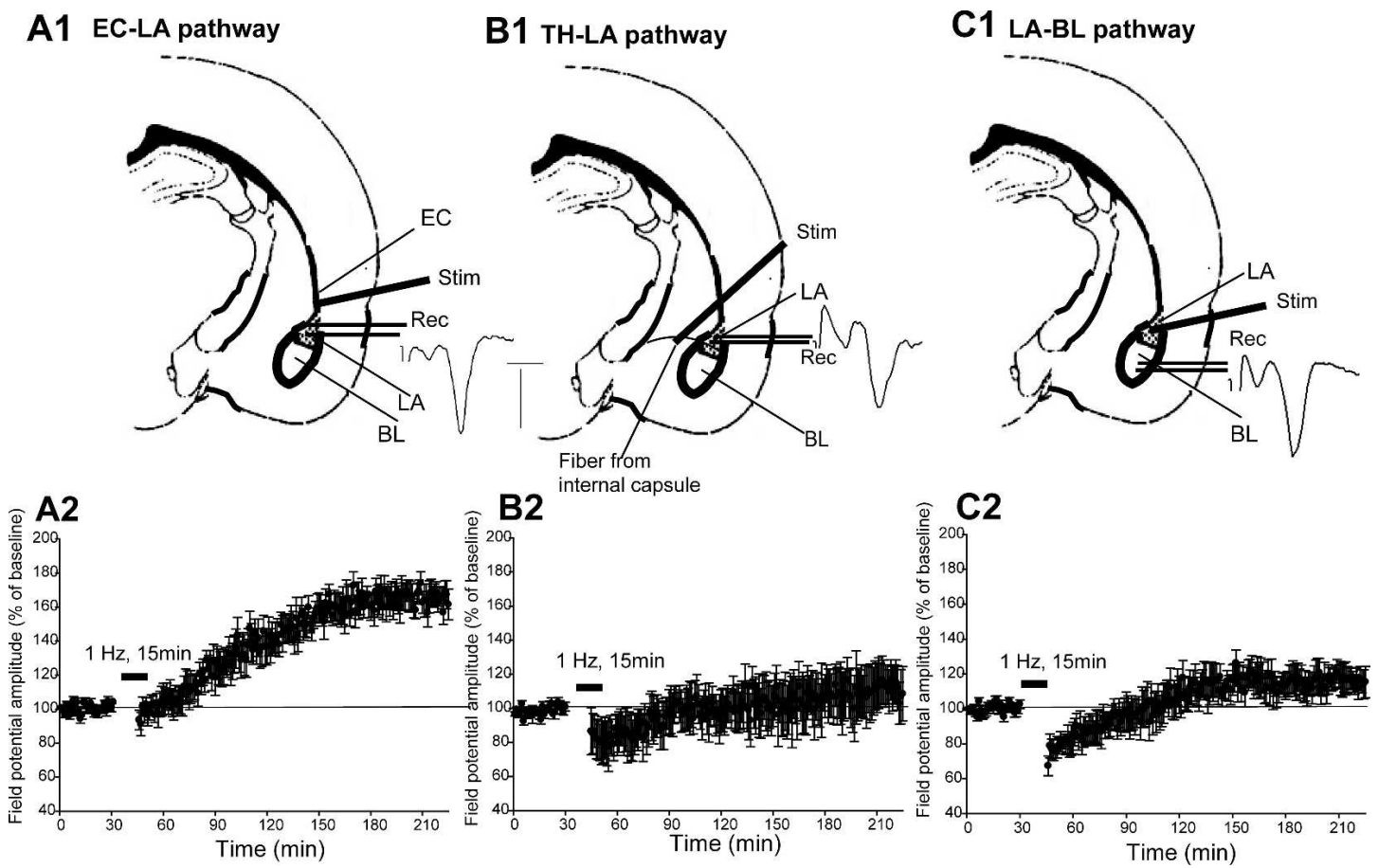

Figure 1. Plastic changes induced by LFS in different synaptic pathways of the amygdala. (A1) Schematic illustration of stimulating and recording site of EC-LA pathway in a coronal brain slice. The inset shows the representative field potential recorded in this pathway. (A2) LFS (1 Hz, $15 \mathrm{~min})$ induced L-LTP in the EC-LA pathway. Calibration: $3 \mathrm{msec}, 1 \mathrm{mV}$. (B1) Schematic illustration of stimulating and recording site of the TH-BL pathway. The inset shows the representative field potential in this pathway. (B2) LFS induced a transient synaptic depression, followed by a weak potentiation in this pathway. (C1) Schematic illustration of stimulating and recording site of the LA-BL pathway. The inset shows the representative field potential in this pathway. (C2) LFS did not induce L-LTP in this pathway. 
A

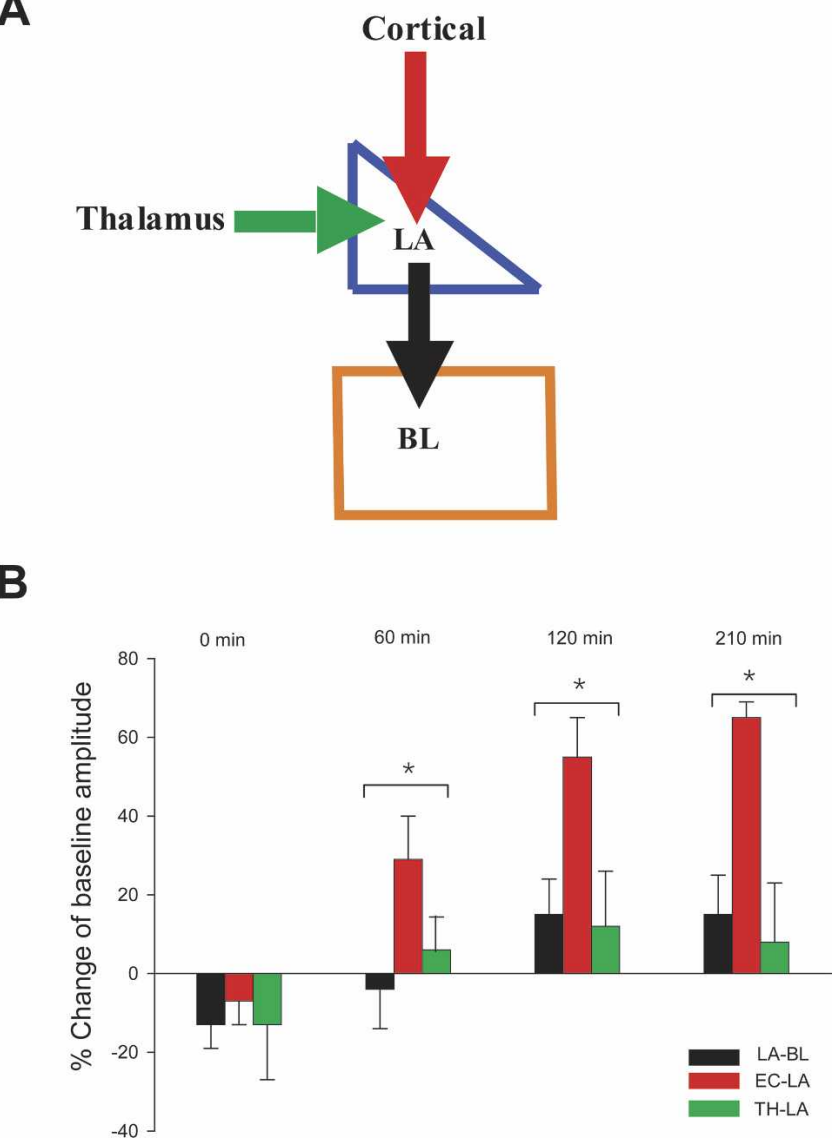

Figure 2. A comparison of plastic changes induced by LFS in three different pathways of amygdala. (A) Schematic model shows the major inputs to the lateral amygdala (LA) and the output from LA to the basolateral amygdala (BL). (B) Histograms show the comparisons of plastic changes induced by LFS in three different synaptic pathways above at different time points after LFS. (Black bars) LA-BL pathway; (red bars) EC-LA pathway; (green bars) TH-LA pathway. There are significant differences in the plastic changes induced by LFS between these pathways. $* P<0.01$, ANOVA.

both the early and the late component of LFS L-LTP require the synthesis of new protein.

\section{5-HT4, Dl, and $\boldsymbol{\beta}$-adrenergic receptor modulate L-LTP produced by LFS}

The three major neurotransmitters receptors positively coupled to the cAMP/PKA signaling pathway are the dopamine D1 receptor, the 5-HT4 receptor, and the $\beta$-adrenergic receptor. These receptors are all present in moderately dense levels in the amygdala (Ordway et al. 1988; Waeber et al. 1996; Asan 1998), and have been found to be involved in the modulation of certain forms of synaptic plasticity in the amygdala (Huang et al. 2000; Huang and Kandel 2007) as well as in the modulation of amygdala-based emotional behavior (Lamont and Kokkinidis 1998; Barnes and Sharp 1999; Guarraci et al. 1999). Therefore, we asked: Are any of these transmitter receptors involved in the modulation of LFS L-LTP? We first examined the role of the antagonists. As shown in Figure 4A, 5-HT4 receptor antagonist (RS39604, $25 \mu \mathrm{M}$ ) completely blocked the LFS-LTP in EC-LA pathway. (Control: $160 \pm 9 \%, n=6$; RS30604: $95 \pm 6 \%, n=6$, $3.5 \mathrm{~h}$ after LFS, $t=7.1, P<0.01)$. D1/D5 receptor antagonist (SCH23390, $2 \mu \mathrm{M}$ ) not only blocked L-LTP (Control: $163 \pm 8 \%$, $n=6$; SCH: $99 \pm 11 \%, n=6$, measured $3.5 \mathrm{~h}$ after LFS, $t=5.3$, $P<0.01)$, but also induced a profound early synaptic depression (Control: $110 \pm 9 \% ; n=6$; SCH: $72 \pm 10 \%, n=6$; measured 30 min after LFS, $t=4.1, P<0.01$, measured 30 min after LFS; Fig. 4B). Similarly, we found that L-LTP induced by LFS was completely blocked by $\beta$-antagonist propranolol $(1 \mu \mathrm{M})$ (Control: $166 \pm 9 \%, n=6$; Propranolol: $86 \pm 14 \%, n=6$, measured $3.5 \mathrm{~h}$ after LFS, $t=5.1, P<0.01$ ) (Fig. $4 \mathrm{C}$ ). A comparison of the effects of the antagonists of these receptors is shown in Figure 6A, below. ANOVA revealed that there is no significant difference between the effects of different antagonists $\left(F_{(2,12)}=0.25\right.$, $P>0.5)$.

\section{A}

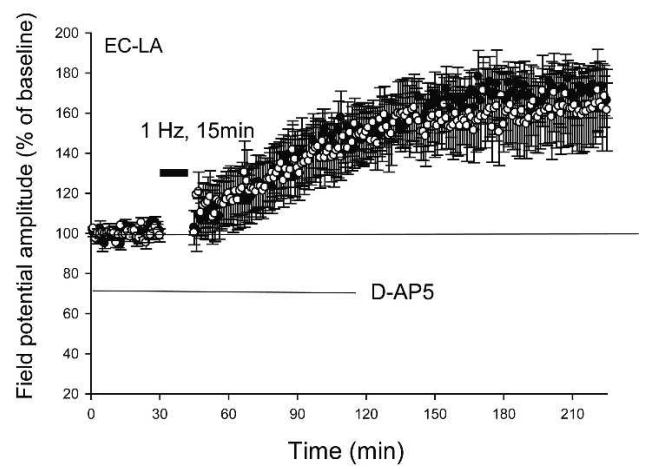

B

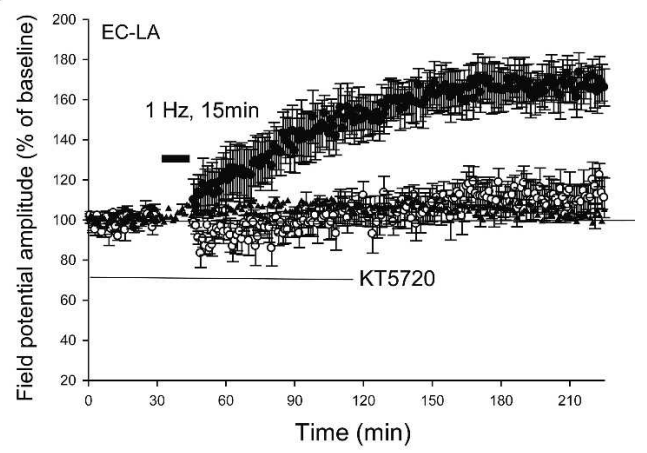

C

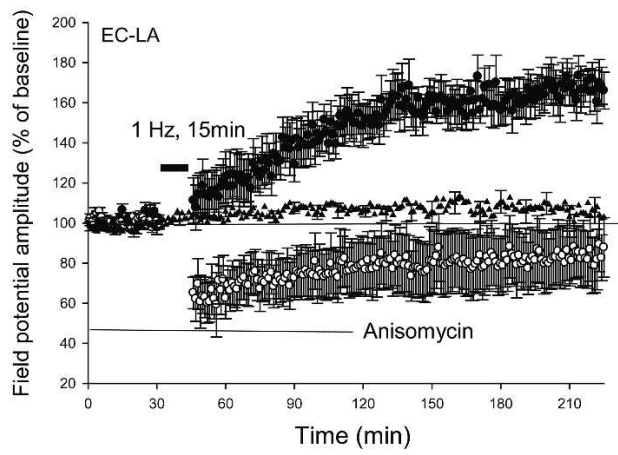

Figure 3. LFS L-LTP in the amygdala is dependent on PKA and new protein synthesis. (A) NMDA receptors antagonist D-APV $(50 \mu \mathrm{M})$ did not block LFS L-LTP. ( $)$ Control; (O) D-APV + LFS. (B) Inhibitor of PKA KT5720 $(1 \mu \mathrm{M})$ completely blocked the LFS L-LTP. (๑) Control; (O) KT5720 + LFS; $(\Delta)$ KT5720 alone; $(n=5)$. (C) LFS induced a synaptic depression in the presence of anisomycin. ( Control; $(O)$ Anisomycin + LFS; $(\boldsymbol{\Delta})$ Anisomycin alone; $(n=5)$. 
We next examined the effect of agonists of these receptors. Interestingly, we found that even though the effects of the antagonists are similar, the effects among the agonists of these receptors are quite different. As reported previously (Huang and Kandel 2007), the partial agonist of 5-HT4 receptor RS67333 (50 $\mu \mathrm{M})$ also induced L-LTP in the EC-LA pathway in the presence of Zimelidine (100 $\mu \mathrm{M}$, a selective serotonin uptake inhibitor) $(148 \pm 13 \%, n=6$, measured $3.5 \mathrm{~h}$ after LFS). However, coapplication of the 5-HT4 agonist RS67333 and LFS ( $1 \mathrm{~Hz}, 15 \mathrm{~min})$ induced a large synaptic depression during the first hour, which is significantly different from RS67333 without pairing of LFS (RS67333 + Zimelidine: $84 \pm 5 \%, n=6$; RS67333 + Zimelidine + LFS: $53 \pm 3 \%, n=5$; Zimelidine + LFS: $99 \pm 9 \%, n=5$, measured $30 \mathrm{~min}$ after LFS, $F_{(2,14)}=8, P<0.01$, ANOVA, measured 30 min after LFS). In addition, LFS-induced L-LTP was also blocked in the presence of RS67333 (102 $\pm 9 \%, n=6$, measured $3.5 \mathrm{~h}$ after LFS; Fig. 5A). As reported previously, brief application of $\beta$-adrenergic receptor agonist Isopretenelol (ISO, $15 \mu \mathrm{M}$ ) induced L-LTP (Huang et al. 2000). Co-application of ISO with LFS ( $1 \mathrm{~Hz}, 15 \mathrm{~min})$ did not alter the L-LTP induced by LFS (ISO: $141 \pm 6 \%, n=5$; ISO + $1 \mathrm{~Hz}: 145 \pm 9 \%, n=6$, measured $3.5 \mathrm{~h}$ after LFS, $P>0.5$; Fig. 5B). In contrast to the agonist of $\beta$-adrenergic and 5-HT4 receptors, the D1 receptor agonist 6-APB $(50 \mu \mathrm{M})$ did not elicit L-LTP in the EC-LA pathway $(101 \pm 4 \%, n=5$, measured $3.5 \mathrm{~h}$ after). Co-application of D1 agonist with LFS induced only a short-lasting synaptic depression (75 $\pm 5 \%$, $n=5$, measured $30 \mathrm{~min}$ after LFS) and the LFS L-LTP was also blocked in the presence of 6 -APB $(102 \pm 14 \%, n=5$, measured $3.5 \mathrm{~h}$ after; Fig. 5C). A comparison of the effects of co-application of different agonists with LFS is shown in Figure 6B. ANOVA revealed that the changes of synaptic weight $(30 \mathrm{~min}$ and $3.5 \mathrm{~h}$ after LFS) in the presence of D1 receptor, 5-HT4 receptor, and $\beta$-adrenergic receptor agonist are significantly different $\left(F_{(2,12)}=4.5, P<0.05\right)$.

\section{Discussion}

Low-frequency stimulation elicits a protein synthesis-dependent L-LTP in the lateral amygdala

The changes in synaptic strength produced by low-frequency stimulation (LFS) are bidirectional and depend on the age of the animals and the duration and patterns of stimulation (Wagner and Alger 1995; Milner et al. 2004; Huang and Kandel 2006; Lante et al. 2006a,b). In contrast to the long-term synaptic depression induced by LFS ( $1 \mathrm{~Hz}, 15 \mathrm{~min}$ ) in the amygdala of young animals (Wang and Gean 1999; Kaschel et al. 2004), we demonstrate that in adult animals, LFS (1 Hz, $15 \mathrm{~min})$ induces a protein synthesis-dependent L-LTP in the EC-LA pathway of amygdala. In our previous studies, we had found that LFS induces a protein synthesis-dependent late phase of L-LTP in the hippocampus of adult animals (Huang and Kandel 2005, 2006). The present finding in the amygdala provides further evidence for the existence of LFS L-LTP.

The LFS L-LTP in the amygdala is importantly different from the HFS L-LTP, in that LFS L-LTP is not dependent on the activation of NMDA receptors (Li et al. 2001). This implies that there are at least two different forms of L-LTP in the EC-LA pathway, and they may be correlated with perhaps different aspects of memory for fear. Indeed, in slices taken from fear-conditioning animals, HFS-induced LTP was attenuated, whereas LTP induced by LFS was changed in an opposite direction (enabling the induction of LTP) (Schroeder and Shinnick-Gallagher 2004, 2005). Similarly, HFS-induced L-LTP was impaired, while LFS-induced L-LTP was enhanced in the hippocampus of the aged mice with memory loss (Bach et al. 1999; Huang and Kandel 2006). Thus,
A

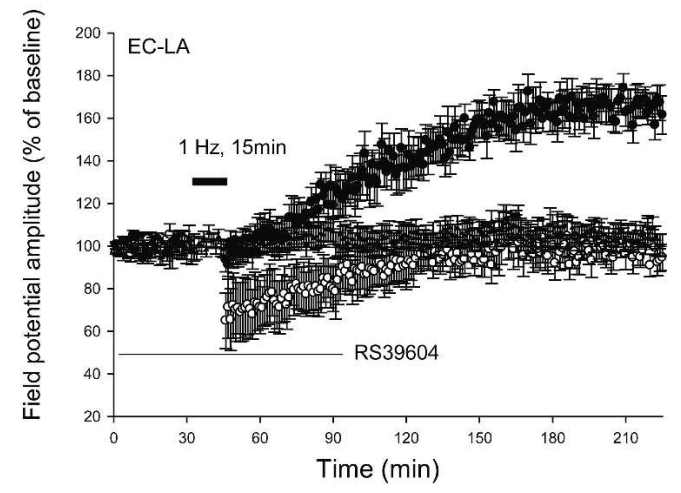

B

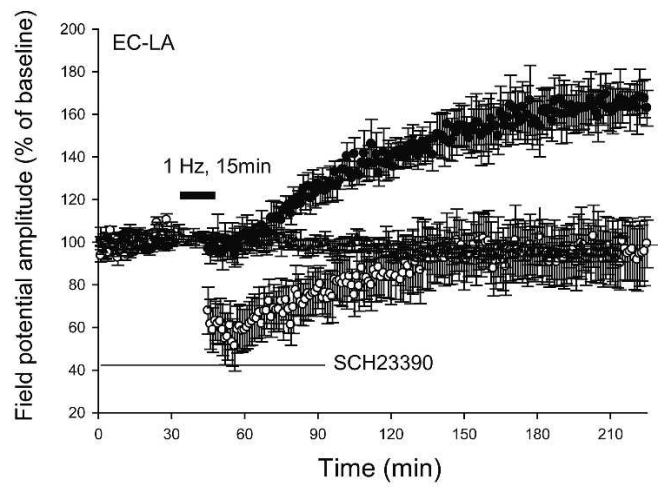

C

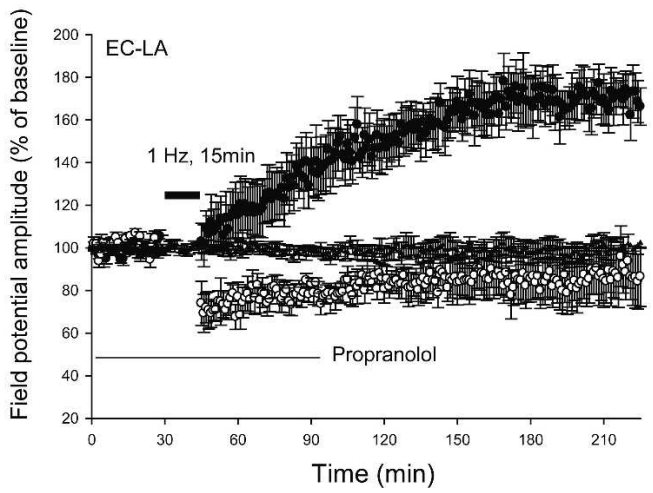

Figure 4. The effects of 5-HT4, D1, and $\beta$-adrenergic receptor antago-

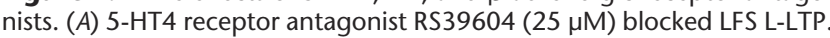
(•) LFS; (O) LFS + RS39604; RS39604 alone did not alter the baseline synaptic response $(\boldsymbol{\Delta}, n=5)$. (B) D1 receptor antagonist $\mathrm{SCH} 23390$ (2 $\mu \mathrm{M})$ blocked LFS L-LTP. ( $)$ LFS. (O) LFS $+\mathrm{SCH} ;(\boldsymbol{\Lambda}, n=5) \mathrm{SCH}$ alone did not alter the baseline synaptic response. (C) $\beta$-Adrenegic receptor antagonist propranolol $(1 \mu \mathrm{M})$ blocked LFS L-LTP. ( $(\bullet)$ LFS; $(\bigcirc)$ LFS + Propranolol; $(\boldsymbol{\Lambda}, n=5)$ Propranolol alone did not alter the baseline synaptic response.

LFS L-LTP in the amygdala may represent a distinct synaptic mechanism for the acquisition and storage of different forms of memory for fear. The finding that L-LTP could be elicited by LFS is of particular interest, because LFS seems to better match the physiological responsiveness of amygdala neurons under natural conditions (Pare and Collins 2000), and EEG waves of 1-4 Hz in the brain have been shown to play a critical role in the consolidation of various forms of memory (Kenny et al. 2003; Higgins et al. 2004). 
A

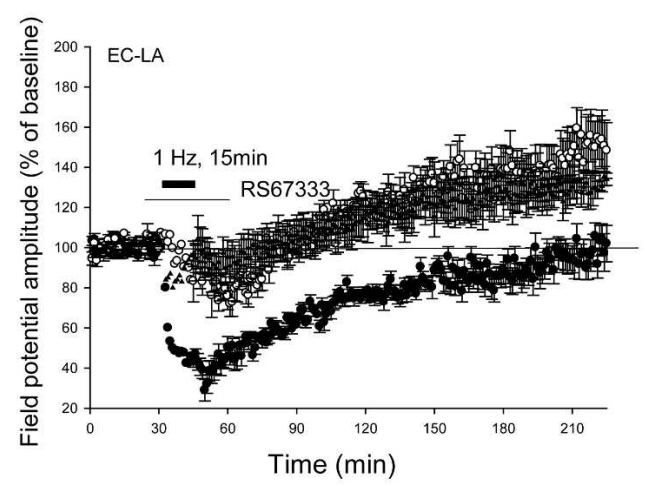

B

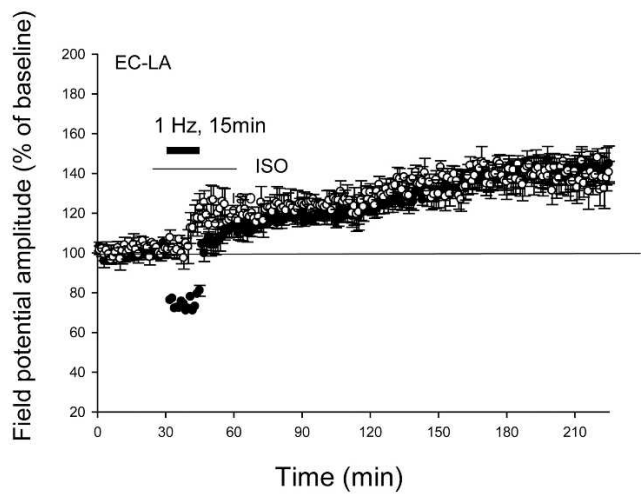

C

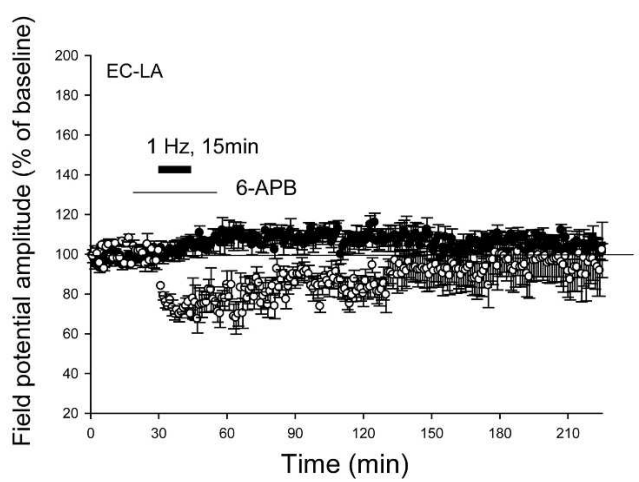

Figure 5. The effects of 5-HT4, D1, and $\beta$-adrenergic receptor agonists. (A) 5-HT4 receptor agonist RS67333 $(50 \mu \mathrm{M}$, perfused for $25 \mathrm{~min}$, in the presence of Zimelidine, $100 \mu \mathrm{M}$ ) induced L-LTP. Co-application RS67333 and LFS induced a profound early synaptic depression. (O) RS67333 + Zimelidine; (•) RS67333 + Zimelidine + LFS. (A) Zimelidine + LFS. (B) $\beta$-Adrenergic receptor agonist Isoproterenol (ISO, $15 \mu \mathrm{M}$, perfused for $25 \mathrm{~min})$ induced L-LTP. Co-application ISO and LFS $(1 \mathrm{~Hz}$, $15 \mathrm{~min}$ ) did not alter the LFS L-LTP. (O) ISO; (৩) ISO + LFS. (C) D1 receptor agonist 6-APB (50 $\mu \mathrm{M}$, perfused for $25 \mathrm{~min})$ did not induce L-LTP. Co-application 6-APB and LFS induced a weak synaptic depression. (•) 6-APB; (O) 6-APB + LFS.

LFS-induced L-LTP in the amygdala is pathway specific Different synaptic pathways within the circuits of amygdala may play different roles in the acquisition and storage of fear memory. Auditory stimuli, which are critical for Pavlovian fear conditioning, reach the LA by means of the TH-LA or the EC-LA. These inputs are essential for the formation of CS-US convergence in the LA. In contrast, the LA-BL pathway is an output pathway of LA and may play a certain role in the expression of fear conditioning, but not in its acquisition (Amorapanth et al. 2000; Anglada-Figueroa and Quirk 2005; Corcoran and Quirk 2007). We were interested in knowing whether there are differences in LTP between these pathways. Although different time courses of LTP induced by high-frequency stimulation (theta bursts) have been reported in the thalamic and cortical inputs (Doyere et al. 2003), the difference in the induction of LTP elicited by low-frequency stimulation between EC-LA, TH-LA, and LA-BL pathways has not been studied. Here we find that L-LTP induced by LFS is highly pathway specific. LFS L-LTP can only be elicited in the EC-LA pathway, but not in the TH-LA and LA-BL pathways. This pathway specificity could result from the different inhibitory influences caused by GABAergic interneurons (Heinbockel and Pape 2000; Fu and Shinnick-Gallagher 2005), different structural features in dendritic spines (Humeau et al. 2005), and different levels in the activity of protein phosphatase induced by LFS (Moody et al. 1998; Huang and Kandel 2005). Indeed, the pathway-specific changes of synaptic strength induced by lowfrequency stimulation have been previously described in hippocampus, where low-frequency stimulation $(1 \mathrm{~Hz})$ induces LTP in the Shaffer-Collateral pathway of the CA1 region, but not in the CA3 region (Lante et al. 2006a). Theta frequency stimulation (5 $\mathrm{Hz}$ ) elicits LTP in the CA1-subiculum synaptic pathway, but not in the CA3-CA1 synaptic pathway (Huang and Kandel 2005). In the amygdala, LFS ( $5 \mathrm{~Hz}$ ) induces LTD in the TH-LA pathway of young rat, but not in the EC-LA pathway (Heinbockel and Pape 2000). This pathway and region-specific property of synaptic plasticity may represent the regulation of signal discrimination in the neural network and may play an important role in the acquisition and storage of memory.

\section{Heterosynaptic modulation of LFS L-LTP \\ in the amygdala}

Heterosynaptic modulation is thought to be essential for the stablization of synaptic plasticity in both Aplysia and mammalian brain (Bailey et al. 2000). A requirement of heterosynaptic modulation by dopaminergic, $\beta$-adrenergic, and 5 -HT inputs has been shown in the protein synthesis-dependent late-phase LTP induced by HFS in hippocampus and amygdala (Huang and Kandel 1995a,b, 2007; Huang et al. 2000). The present findings show that synaptic plasticity induced by low-frequency stimulation has a similar requirement for heterosynaptic modulation, as does HFS. Interestingly, we find that although the antagonists of 5 -HT4, D1, and $\beta$-adrenergic receptors all block LFS LTP, the agonists of the three receptors produce distinctive effects. How does one interpret this difference? One possible explanation is that while D1, $\beta$-adrenergic, and 5 -HT4 receptors are all positively coupled to PKA, the PKA levels induced by the activation of these receptors may be different, partly due to the different densities or different sensitivities of these receptors. Co-application of LFS and agonists of these receptors may therefore produce different synergistic effects on the activation of PKA and different changes of synaptic weight (Brandon et al. 1995; Tzounopoulos et al. 1998). The different effect of the agonists of D1, 5-HT, and dopamine receptor suggests that each receptor has its own modulatory role in the network activity within the amygdala. Thus, dopaminergic, noradrenergic, and serotonergic pathways are found to play different roles in the regulation of amygdala-based emotional memory. For instance, infusion of D1 receptor antagonist into the amygdala inhibits the acquisition of fear conditioning and impairs the extinction of fear memory (Guarraci et al. 1999; Inoue et al. 2000; El-Ghundi et al. 2001). On the other hand, intra-amygdala infusion of the $\beta$-adrenergic receptor 


\section{A Antagonists}

(1) LFS+antagonist (30 min after LFS)
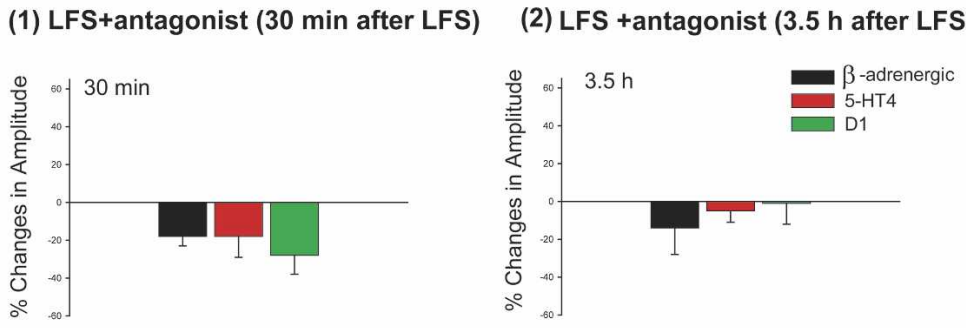

\section{B Agonists}

(1) LFS+agonists (30 min after LFS)

(2) LFS+agonists (3.5 $\mathrm{h}$ after LFS)

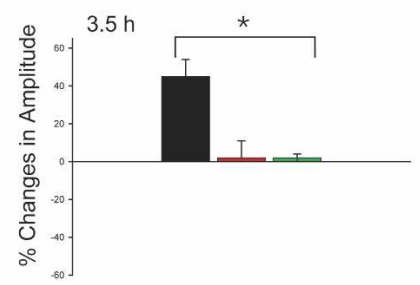

(3) Agonist alone (3.5 h after)

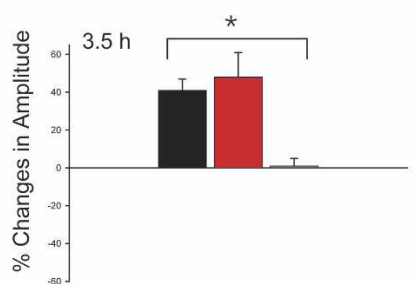

constantly perfused with ACSF at a rate of $2 \mathrm{~mL} / \mathrm{min}$ and bubbled with $95 \% \mathrm{O}_{2}$ and $5 \% \mathrm{CO}_{2}$. The composition of ACSF was as follows: $124 \mathrm{mM} \mathrm{NaCl}, 1.2 \mathrm{mM} \mathrm{MgSO}{ }_{4}$, $4 \mathrm{mM} \mathrm{KCl}, 1.0 \mathrm{mM} \mathrm{NaH} \mathrm{PO}_{4}, 2 \mathrm{mM}$ $\mathrm{CaCl}_{2}, 26 \mathrm{mM} \mathrm{NaHCO}_{3}$, and $10 \mathrm{mM}$ Dglucose. The temperature of the slice was maintained at $27^{\circ} \mathrm{C}$. Experiments were started 2-3 h after slices were dissected.

Extracellular recordings were made using ACSF-filled glass electrodes (1-3 M). Stimuli were delivered at a rate of one per minute $(0.017 \mathrm{~Hz}, 0.05-\mathrm{msec}$ pulse duration) through concentric bipolar stainless-steel electrodes $(25 \mu \mathrm{M}$ wire diameter, CBBRC75, FHC Inc.). To produce L-LTP in the EC-LA synaptic pathway, the stimulating electrodes were placed in the external capsule (EC), which contained fibers from the auditory cortex to the lateral amgdala (ECLA). To produce L-LTP in the TH-LA, the stimulating electrodes were placed in thalamic afferent fiber to the lateral amygdala, which is located in the ventral part of the striatum just above the central nucleus of the amygdala (Huang et al. 2000). To record from EC-LA and TH-LA pathways, recording electrodes were placed in the lateral amygdala (LA). To produce L-LTP in the LA-BL synaptic pathway, the stimulating electrodes were placed in the LA, and the recording electrodes were placed in the basolateral subdivision of amygdala. The stimulation intensity was adjusted to evoke the field potential that was about 50\%-60\% of maximal amplitude. Baseline values were acquired over a period of $30 \mathrm{~min}$ before giving the LTP-inducing stimulation. To elicit LTP by low-frequency stimulation, $1 \mathrm{~Hz}$ (15 min, 900 pulses) stimulation was used. Changes in synaptic strength were expressed relative to the normalized baseline (mean \pm SEM). Statistical comparisons were performed using Student's $t$-test and ANOVA.

For bath application, the following drugs were made in water or in DMSO and stored as concentrated stock solution and diluted 1000-fold when applied

antagonist, propranolol, disrupts the reconsolidation, but not the consolidation of fear conditioning (Debiec and Ledoux 2004). Clinically, dopaminergic, serotonergic, and noradrenergic systems also play different roles in the mental disorders. Abnormalities in dopaminergic synaptic transmission are thought to contribute to schizophrenic symptoms; abnormalities in the serotoninergic system are involved in depression and anxiety; noradrenergic synaptic transmission is more critical for the posttraumatic stress disorder (PTSD) (Kandel 2000). Taken together, it appears that these modulatory systems coexist in the amygdala, and the expression and the storage of emotional behavior requires cross-talk between multiple neurotransmitters.

\section{Materials and Methods}

C57/B6 mice (8-12 wk old) were quickly decapitated, the whole brain was placed in ice-cold artificial cerebrospinal fluid (ACSF), and a block of tissue containing the amygdala was removed. Coronal sections $(400 \mu \mathrm{M})$ were cut and transferred to an interface chamber (Fine Science Tools). Slices were submerged and to the perfusion solution: KT5720 (Biomol, dissolved in DMSO) Anisomycin (Sigma, in water), D-APV [D-(-)-2-amino-5phosphonopentanotic acid; Sigma, in water], Zimelidine (Sigma, in water), RS39604 (Tocris, in DMSO), RS67333 hydrochloride (Tocris, in DMSO), SCH23390 (Sigma, in water), Propranolol (Sigma, in water), Isoproterenol (Sigma, in water), 6-Bromo-APB (Sigma, in DMSO). The final concentration of DMSO is $0.1 \%$. In control experiments, $0.1 \%$ DMSO was used and no effect on baseline recording was found.

\section{Acknowledgments}

We thank Juan Marcos Alarcon and Joseph Rayman for critical reading of the manuscript and helpful comments. This work was supported by the Howard Hughes Medical Institute, the New York State Psychiatric Institute and NIMA grant MH50733, and NIH Program Project grant on Amygdala and Anxiety States (E.R.K.)

\section{References}

Albrecht, D. 2007. Angiotensin-(1-7)-induced plasticity changes in the lateral amygdala are mediated by COX-2 and NO. Learn. Mem. 14: $177-184$.

Amorapanth, P., Ledoux, J.E., and Nader, K. 2000. Different lateral 
amygdala outputs mediate reactions and actions elicited by a fear-arousing stimulus. Nat. Neurosci. 3: 74-79.

Anglada-Figueroa, D. and Quirk, G.J. 2005. Lesion of the basal amygdala block expression of conditioned fear but not extinction. J. Neurosci. 25: $9680-9685$.

Asan, E. 1998. The catecholaminergic innervation of the rat amygdala. Adv. Anat. Embryo. Cell Biol. 142: 1-118.

Bach, M.E., Barad, M., Son, H., Zhuo, M., Lu, Y.-F., Shih, R., Mansuy, I., Hawkins, R.D., and Kandel, E.R. 1999. Age-related defects in spatial memory are correlated with defects in the late phase of hippocampal long-term potentiation in vitro and attenuated by drugs that enhance the cAMP signaling pathway. Proc. Natl. Acad. Sci. 96: $5280-5285$.

Bailey, C.H., Giustetto, M., Huang, Y.-Y., Hawlins, R.D., and Kandel, E.R. 2000. Is heterosynaptic modulation essential for stabilization hebbian plasticity and memory? Nat. Rev. Neurosci. 1: 1-20.

Barnes, N.M. and Sharp, T. 1999. A review of central 5-HT receptors and their function. Neuropharmacology 38: 1083-1152.

Blair, H.T., Schafe, G.E., Bauer, E.P., Rodrigus, S.M., and Ledoux, J.E. 2001. Synaptic plasticity in the lateral amygdala: A cellular hypothesis of fear conditioning. Learn. Mem. 8: 229-242.

Brandon, E.P., Zhuo, M., Huang, Y.-Y., Qi, M., Gerhold, K.A., Burton, K.A., Kandel, E.R., Mcknight, G.S., and Idzerda, R.L. 1995. Hippocampal long-term depression and depotentiation are defective in mice carrying a targeted disruption of the gene encoding the RI $\beta$ subunit of cAMP-dependent protein kinase. Proc. Natl. Acad. Sci. 92: $8851-8855$.

Corcoran, K.A. and Quirk, G.J. 2007. Activity in prelimbic cortex is necessary for the expression of learned, but not innate fears. $J$. Neurosci. 7: 840-844.

Debiec, J. and Ledoux, J.E. 2004. Disruption of reconsolidation but not consolidation of auditory fear conditioning by noadrenergic blockade in the amygdala. Neuroscience 129: 267-272.

Doyere, V., Schafe, G.E., Sigurdsson, T., and Ledoux, J.E. 2003. Long-term potentiation in free moving rats reveals asymmetries in thalamic and cortical inputs to the lateral amygdala. Eur. J. Neurosci. 17: $2703-2715$.

El-Ghundi, M., O'Dowd, B.F., and George, S.R. 2001. Prolonged fear responses in mice lacking dopamine D1 receptor. Brain Res. 892: $86-93$.

Fu, Y. and Shinnick-Gallagher, P. 2005. Two intra-amygdaloid pathways to the central amygdala exibit different mechanisms of long-term potentiaiton. J. Neurophysiol. 3: 3012-3015.

Guarraci, F.A., Frohardt, R.J., and Kapp, B.S. 1999. Amygdaloid D1 dopamine receptor involvement in Pavlovian fear conditioning Brain Res. 827: 28-40.

Heinbockel, T. and Pape, H.-C. 2000. Input-specific long-term depression in the lateral amygdala evoked by theta frequency stimulation. J. Neurosci. 20: RC68.

Higgins, G.A., Ballard, T.M., Kew, J.N., Richards, J.G., Kemp, J.A., Adam, G., Woltering, T., Nakanishi, S., and Mutel, V. 2004. Pharmacological manipulation of mGlu2 receptors influences cognitive performance in the rodent. Neuropharmacology 46: 907-917.

Huang, Y.-Y. and Kandel, E.R. 1995a. D1/D5 receptor agonists induce a protein synthesis-dependent late potentiation in the CA1 region of hippocampus. Proc. Natl. Acad. Sci. 92: 2446-2450.

Huang, Y.-Y. and Kandel, E.R. 1995b. Modulation of both the early and the late phase of mossy fiber LTP by the activation of $\beta$-adrenergic receptors. Neuron 16: 611-617.

Huang, Y.-Y. and Kandel, E.R. 1998. Postsynaptic induction and PKA-dependent expression of LTP in the lateral amygdala. Neuron 21: $169-178$..

Huang, Y.-Y. and Kandel, E.R. 2005 Theta frequency stimulation up-regulates the synaptic strength of the pathway from CA1 to subiculum region of hippocampus. Proc. Natl. Acad. Sci. 102: $232-237$.

Huang, Y.-Y. and Kandel, E.R. 2006. Age-related enhancement of a protein synthesis-dependent late phase of LTP induced by low frequency paired-pulse stimulation in hippocampus. Learn. Mem. 13: $298-306$.

Huang, Y.-Y. and Kandel, E.R. 2007. 5-HT induces a PKA/MAPK-mediated and micromolecular synthesis-dependent late phase of LTP in the amygdala. J. Neurosci. 27: 3111-3119.

Huang, Y.-Y., Martin, K.C., and Kandel, E.R. 2000. Both protein kinase A and mitogen-activated protein kinase are required in the amygdala for the micromolecular synthesis-dependent late phase of long-term potentiation. J. Neurosci. 20: 6317-6325.

Humeau, Y., Herry, C., Kemp, N., Shaban, H., Fourcaudot, E., Bissiere, S., and Luthi, A. 2005. Dendritic spine heterogeneity determines afferent-specific hebbian plasticity in the amygdala. Neuron 45: $119-131$.
Inoue, T., Izumi, T., Maki, Y., Muraki, I., and Koyama, T. 2000. Effect of the dopamine D1/5 antagonist SCH 23390 on the acquisition of conditioned fear. Pharmacol. Biochem. Behav. 66: 573-578.

Kandel, E.R. 2000. Disorders of mood: Depression, mania, and anxiety disorders In Principles of neural science, 4 th ed. (eds. E.R. Kandel et al.), pp. 1209-1226. McGraw-Hill, New York

Kaschel, T., Schubert, M., and Albrecht, D. 2004. Long-term depression in horizontal slices of the rat lateral amygdala. Synapse 53: 141-150.

Kenny, P.J., Gasparini, F., and Markou, A. 2003. Group II metabotropic and $\alpha$-amino-3-hydroxy-5-methyl-4-isoxazole propionate (AMPA)/kainate glutamate receptors regulate the deficit in brain reward function associated with nicotine withdrawal in rats. $J$. Pharmacol. Exp. Ther. 306: 1068-1076.

Lamont, E.W. and Kokkinidis, L. 1998. Infusion of the dipamine D1 receptor antagonist SCH 23390 into the amygdala blocks fear expression in a potentiated startle paradigm. Brain Res. 795: 128-136.

Lante, F., de Jesus Ferreira, M.C., Guiramand, J., Recasens, M., and Vignes, M. 2006a. Low frequency stimulation induces a new form of LTP, metabotropic glutamate (mGlu5) receptor-and PKA dependent in CA1 area of the rat hippocampus. Hippocampus 16: 345-360.

Lante, F., Cavalier, M., Cohen-Solal, C., Guiramand, J., and Vignes, M. 2006b. Developmental switch from LTD to LTP in low frequency-induced plasticity. Hippocampus 16: 981-989.

Ledoux, J.E. 2000. Emotion circuits in the brain. Annu. Rev. Neurosci. 23: $155-184$.

Li, H., Chen, A., Xing, G., Wei, M.-L., and Rogawski, M.A. 2001. Kainate receptor-mediated heterosynaptic facilitation in the amygdala. Nat. Neurosci. 4: 612-620.

Malenka, R.C. and Bear, M.F. 2004. LTP and LTD: An embarrassment of riches. Neuron 44: 5-21.

Milner, A., Cummings, D.M., Spencer, J.P., and Murphy, K.P.S.J. 2004. Bi-directional plasticity and age-dependent long-term depression at mouse CA3-CA1 hippocampal synapses. Neurosci. Lett. 367: 1-5.

Moody, T., Tomas, T.J., Makhinson, M., and O'Dell, T. 1998. 5-Hz stimulation of CA3 pyramidal cell axons induces a $\beta$-adrenergic modulated potentiation at synapses on CA1, but not CA3, pyramidal cells. Brain Res. 794: 75-79.

Ordway, G.A., Gambarana, C., and Frazer, A. 1988. Quantitative autoradiaography of central $\beta$-adrenoceptor subtype: Comparison of the effects of chronic treatment with desipramine or centrally administered L-isoproterenol. J. Pharmacol. Exp. Ther. 247: 379-389.

Pare, D. and Collins, D.R. 2000. Neuronal correlates of fear in the lateral amygdala: Multiple extracellular recordings in conscious cats. $J$. Neurosci. 20: 2701-2710.

Rammes, G., Steckler, T., Kresse, A., Schutz, G., Zieglgänsberger, W., and Lutz, B. 2000. Synaptic plasticity in the basolateral amygdala in transgenic mice expression dominant-negative cAMP response element-binding protein (CREB) in forebrain. Eur. J. Neurosci. 12: $2534-2546$.

Rammes, G., Eder, M., Dodt, H.-U., Kochs, E., and Zieglgansberger, W. 2001. Long-term depression in the basolateral amygdala of the mouse involves the activation of interneurons. Neuroscience 107: 85-97.

Schroeder, B.W. and Shinnick-Gallagher, P. 2004. Fear memories induce a switch in stimulus response and signaling mechanisms for long-term potentiaton in the lateral amygdala. Eur. J. Neurosci. 20: $549-556$.

Schroeder, B.W. and Shinnick-Gallagher, P. 2005. Fear learning induces persistent facilitation of amygdala synaptic transmission. Eur. J. Neurosci. 22: 1775-1783.

Stefanacci, L., Farb, C.R., Pitkanen, A., Go, G., Ledoux, J.E., and Amaral, D.G. 1992. Projections from the lateral nucleus to the basal nucleus of amygdala: A light and electron microscopic PHA study in the rat. J. Comp. Neurol. 15: 8259-8301.

Tchekalarova, J. and Albrechet, D. 2007. Angiotensin II suppresses long-term depression in the lateral amygdala of mice via L-type calcium channels. Neurosci. Lett. 415: 68-72.

Tzounopoulos, T., Janz, R., Sudhof, T.C., Nicoll, R.A., and Malenka, R.C. 1998. A role for cAMP in long-term depression at hippocampal mossy fiber synapses. Neuron 21: 837-845.

Waeber, C., Sebben, M., Bockaert, J., and Dumuis, A. 1996. Regional distribution and ontogeny of 5-HT4 binding sites in rat brain. Behav. Brain Res. 73: 259-262.

Wagner, J.J. and Alger, B.E. 1995. GABAergic and developmental influences on homosynaptic LTD and depotentiation in rat hippocampus. J. Neurosci. 15: 1577-1586.

Wang, S.-J. and Gean, P.-W. 1999. Long-term depression of excitatory synaptic transmission in the rat amygdala. J. Neurosci. 19: $10656-10663$

Received March 28, 2007; accepted in revised form May 18, 2007. 


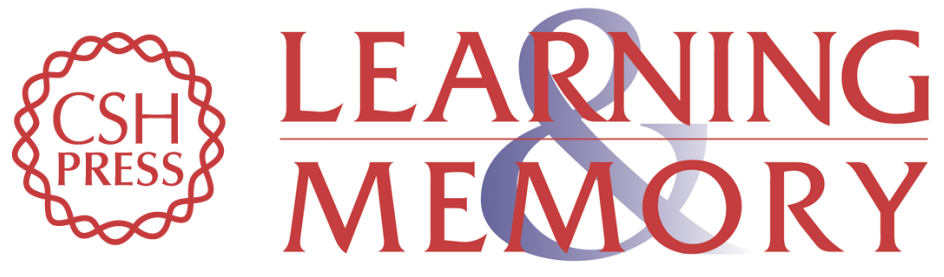

\section{Low-frequency stimulation induces a pathway-specific late phase of LTP in the amygdala that is mediated by PKA and dependent on protein synthesis}

Yan-You Huang and Eric R. Kandel

Learn. Mem. 2007, 14:

Access the most recent version at doi:10.1101//m.593407

References This article cites 48 articles, 16 of which can be accessed free at: http://learnmem.cshlp.org/content/14/7/497.full.html\#ref-list-1

License

Email Alerting Receive free email alerts when new articles cite this article - sign up in the box at the Service top right corner of the article or click here. 